MATEC Web of Conferences 39, 01005 (2016)

DOI: $10.1051 /$ matecconf/20163901005

C Owned by the authors, published by EDP Sciences, 2016

\title{
The effect of fibre layering pattern in resisting bending loads of natural fibre-based hybrid composite materials
}

\author{
Muhamad Shahirul Mat Jusoh ${ }^{1, a}$, Mohd Yazid Yahya ${ }^{2}$ and Nur Izan Syahriah Hussein ${ }^{3}$ \\ ${ }^{1}$ Faculty of Mechanical Engineering, Universiti Teknologi Malaysia, 81310, Skudai, Johor, Malaysia \\ ${ }^{2}$ Centre for composite (CfC) Universiti Teknologi Malaysia, 81310, Skudai, Johor, Malaysia \\ ${ }^{3}$ Faculty of Manufacturing, Universiti Teknikal Malaysia Melaka, Malaysia
}

\begin{abstract}
The effect of fibre layering pattern and hybridization on the flexural properties of composite hybrid laminates between natural fibres of basalt, jute and flax with synthetic fibre of E-glass reinforced epoxy have been investigated experimentally. Results showed that the effect fibre layering pattern was highly significant on the flexural strength and modulus, which were strongly dependent on the hybrid configuration between sandwich-like (SL) and intercalation (IC) sequence of fibre layers. In addition, specific modulus based on the variation densities of the hybrid laminates was used to discover the best combination either basalt, jute or flax with E-glass exhibits superior properties concerning on the strength to weight-ratio. Generally, SL sequence of glass/basalt exhibited superior strength and stiffness compared with glass/jute and glass/flax in resisting bending loads. In terms of hybridization effect, glass/jute was found to be the best combination with E-glass compared to the rest of natural fibres investigated in the present study. Hence, the proper stacking sequences and material selection are among predominant factors that influence on mechanical properties and very crucial in designing composite hybrid system to meet the desired requirements.
\end{abstract}

\section{Introduction}

In the 21 st century, the development of eco-friendly, biodegradable, sustainable and renewable resources of materials gains attention exclusively. This kind of green technology development is very crucial to cope with global warming and highly concern with environmental issues. In the United State, manufacturers are encouraged to practice 4 Rs, which are Reduce, Reuse, Repair and Recycle to ensure at the end of product life cycle, it's possible to dispose to the landfill [1]. New perspectives have arisen on the usage of natural fibres due to the special attributes offered and potentially low cost together with their good mechanical performance, such as basalt fibre which is capable to resist at high temperature [2]. The idea to fill these fibres into a polymer matrix is relatively recent and the development of hybrid laminated composites using synthetic and natural fibres could offer very interesting perspectives that have not yet been sufficiently investigated. Furthermore, composite materials are broadly used in various fields and applications currently due to unique properties and characteristics that cannot be realized by conventional material. Hybridization of composite laminates with natural fibres gain attention widely due to the lower density of materials offered, yielding relatively light weight composites with specific properties, low cost, acceptable specific properties, ease of separation, enhanced energy recovery and biodegradability [3 - 4].

However, composite materials also have their own sphere of applications and limitations, therefore selection combination of different materials should be done in a judicious way in order to achieve the desired properties. A number of studies have been performed recently, which suggest that mechanical properties can be possibly tailored using hybridization between synthetic and natural fibres of basalt, jute and flax [5 - 10]. Effect of stacking sequence between jute/glass reinforced polyester resin on flexural loading was studied and it was found that incorporation of glass in jute fibre composites enhances the properties of hybrid composites [11]. Empty fruit bunches (EFB)/jute reinforced epoxy with different layering pattern was investigated and the result indicated that the arrangement of woven jute as a skin and oil palm EFB fibre as a core leads to enhance in flexural strength and modulus [12]. Hybrid composites with different stacking sequences of glass/carbon [13], carbon/basalt [14], jute/glass [15] on the mechanical loadings significantly affected the properties of the laminates. The objectives of the present work are to investigate the effect of fibre layering pattern and hybridization of glass/basalt, glass/jute and glass/flax on flexural loadings. In addition, fracture analysis will be characterized using scanning electron microscopy (SEM) to identify the type of failure modes exhibit by the specimens after testing.

\footnotetext{
${ }^{\mathrm{a}}$ Corresponding author: mshahirul@kktmmasjidtanah.edu.my
} 


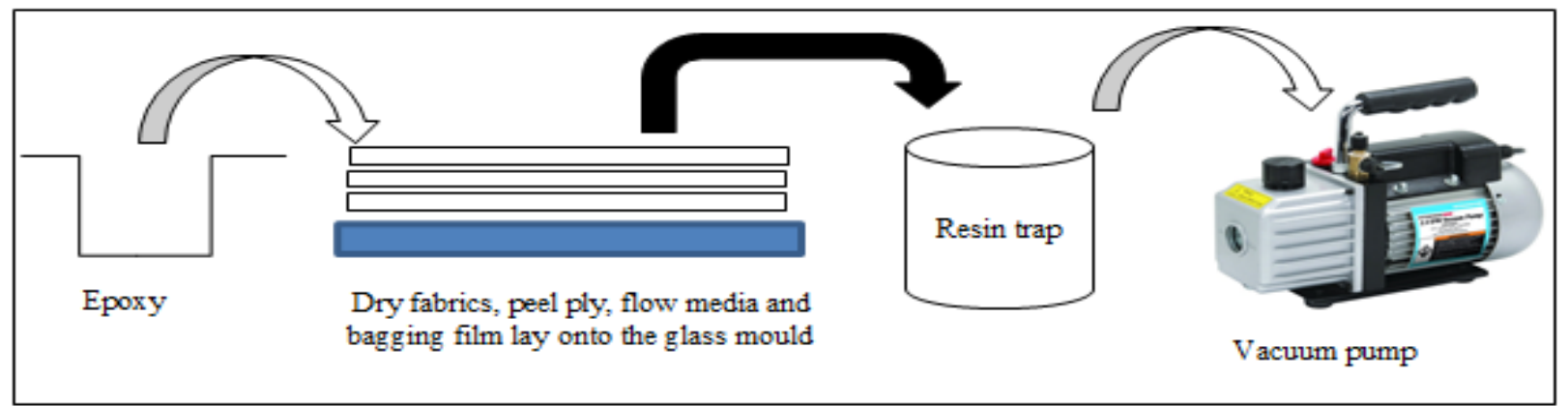

Figure 1. Schematic diagram of VIP

Table 1. Material properties

\begin{tabular}{|c|c|c|c|c|c|}
\hline Fibre & $\begin{array}{c}\text { Arial weight } \\
\left(\mathbf{g} / \mathbf{m}^{\mathbf{2}}\right)\end{array}$ & Density $\left(\mathbf{g} / \mathbf{c m}^{\mathbf{3}}\right)$ & $\begin{array}{c}\text { Tensile strength } \\
\mathbf{( M P a )}\end{array}$ & $\begin{array}{c}\text { Tensile Modulus } \\
\mathbf{( G P a )}\end{array}$ & Elongation (\%) \\
\hline E-glass & 600 & 2.5 & $2000-3500$ & $63 \pm 5$ & 0.5 \\
\hline Flax & 200 & 1.5 & $500 \pm 130$ & $50 \pm 10$ & 2 \\
\hline Jute & 290 & 1.46 & $400 \pm 120$ & $40 \pm 10$ & 1.8 \\
\hline Basalt & 200 & 2.7 & $571 \pm 219$ & $63 \pm 18$ & $0.9 \pm 0.3$ \\
\hline Epoxy & - & 1.17 & $85 \pm 10$ & $10.5 \pm 4$ & 0.8 \\
\hline
\end{tabular}

\section{Materials and Methods}

\subsection{Material}

Hybrid composite laminates were produced using reinforcements and matrix as shown in Table 1. Some of the important factors that should be considered in fabricating hybrid composites are the variation in fibre volume or weight fraction, variation in stacking sequence of fibre layers, fibre treatment and environmental conditions [16]. All Natural fibres were supplied by Easy Composite Ltd, UK. Synthetic fibre of E-glass and epoxy resin were supplied by Chemrex Corporation Sdn. Bhd, Selangor, Malaysia. Epoxy resin DM15F3 (A) cured with hardener DM15F3 (B) in the ratio of 5:1 was used as a matrix.

\subsection{Sample fabrication}

Composite panels were fabricated using vacuum infusion process (VIP). A stack of dry reinforcements are laid onto the glass mould which are then sealed with vacuum bag. The applied vacuum creates a pressure differential which is used to literally sucked resin into the dry fabric lay-up via carefully placing of spiral tubing as shown in Figure 1. During infusion stage, vacuum pressure was maintained at $78 \pm 10 \mathrm{KPa}$ using vacuum pump model ECVP425 provided by Easy Composite, UK. Laminates were cured at room temperature for 24 hours, then post- cure in an oven at $60{ }^{\circ} \mathrm{C}$ for 3 hours. For this study, two types of stacking sequences were considered during sample preparation, namely sandwich-like (SL) and intercalation (IC) sequence with the total of 7-plies comprising of E- glass and natural fibres. Details about the hybrid laminated samples as shown in Table 2.

\subsection{Flexural testing}

The ASTM D790-10 standard was strictly followed for 3points bending test. This method covers for determining flexural properties of reinforced and unreinforced plastics inclusive high modulus composites and electrical insulator materials. The test was conducted using universal testing machine, Instron Model 5969 at room temperature. During testing, specimens were loaded with recommended span to depth ratio of 16:1 using a load cell of $10 \mathrm{kN}$ at a crosshead speed of $2.0 \mathrm{~mm} / \mathrm{min}$. At least five identical specimens were tested for each sample and flexural strength was calculated using the following equation [17];

Table 2. Hybrid laminated composites

\begin{tabular}{|c|c|c|c|}
\hline Symbol & Stacking sequence & $\begin{array}{c}\text { Thickness } \\
(\mathbf{m m})\end{array}$ & $\begin{array}{c}\text { Density } \\
\left(\mathbf{g} / \mathbf{c m}^{\mathbf{3}}\right)\end{array}$ \\
\hline S1 & {$\left[\mathrm{G}_{2} / \mathrm{B}_{3} / \mathrm{G}_{2}\right]-\mathrm{SL}$} & 2.1 & 1.85 \\
\hline S2 & {$\left[\mathrm{G}_{2} / \mathrm{J}_{3} / \mathrm{G}_{2}\right]-\mathrm{SL}$} & 4.2 & 1.43 \\
\hline S3 & {$\left[\mathrm{G}_{2} / \mathrm{F}_{3} / \mathrm{G}_{2}\right]-\mathrm{SL}$} & 3.0 & 1.56 \\
\hline S4 & {$[\mathrm{G} / \mathrm{B} / \mathrm{G} / \mathrm{B}]_{\mathrm{S}}-\mathrm{IC}$} & 2.3 & 1.87 \\
\hline S5 & {$[\mathrm{G} / \mathrm{J} / \mathrm{G} / \mathrm{J}]_{\mathrm{S}}-\mathrm{IC}$} & 4.2 & 1.42 \\
\hline S6 & {$[\mathrm{G} / \mathrm{F} / \mathrm{G} / \mathrm{F}]_{\mathrm{S}}-\mathrm{IC}$} & 2.8 & 1.54 \\
\hline Legend $: \boldsymbol{G}-\boldsymbol{g l a s s}, \boldsymbol{B}-$ basalt, J-jute, F-flax \\
\hline
\end{tabular}




$$
\sigma f=3 P L / 2 b d^{2}
$$

where $\sigma f$ is the flexural strength $(\mathrm{MPa}), \mathrm{P}$ is the maximum load $(\mathrm{N}), \mathrm{L}$ is the support span $(\mathrm{mm}), \mathrm{b}$ is the width of beam tested $(\mathrm{mm})$ and $\mathrm{d}$ is the depth of beam tested (mm). Flexural modulus, Ef was calculated using Tangent Modulus of Elasticity using following equation [17] ;

$$
E f=L^{3} m / 4 b d^{3}
$$

Where $E f$ is the modulus of elasticity in bending (MPa), $\mathrm{L}$ is the support span $(\mathrm{mm}), \mathrm{b}$ is the width of beam tested $(\mathrm{mm}), \mathrm{d}$ is the depth of beam tested $(\mathrm{mm})$ and $\mathrm{m}$ is the slope of the tangent to the initial straight-line portion of the load-deflection curve $(\mathrm{N} / \mathrm{mm})$.

\section{Results and Discussion}

\subsection{Effect of stacking sequences on flexural loading}

In general, hybrid laminates which comprising 2 layers of glass as a face sheet and 3 layers of natural fibres either basalt, jute or flax as a core exhibit higher flexural strength and modulus compared with IC sequence as shown in Figure 2(a) and Figure 2(b). SL sequence of glass/basalt (S1) shows $9.7 \%$ and $14.3 \%$ higher of flexural strength and modulus compared with IC sequence (S4). This pattern was similarly observed on glass/jute (S2) versus (S5) and glass/flax (S3) versus (S6). Glass/jute (S2) and (S5) show flexural strength and modulus of $340 \mathrm{MPa}, 17 \mathrm{GPa}$ and $298 \mathrm{MPa}, 15 \mathrm{GPa}$, respectively. Glass/flax (S3) with SL sequence shows $10.5 \%$ and $6 \%$ higher of flexural strength and modulus than IC sequence (S6). Hybrid laminate of glass/jute highly influenced on the effect of stacking sequence based on the findings from this study, compared with glass/basalt and glass/flax. SL sequence of hybrid laminated composites highly significant on flexural loadings and these can be explained due to the behaviour of the hybrid specimens under bending load, whereas upper and lower sides are in tension and compression modes. Two layers of glass put at the extreme sides on SL sequence enable the hybrid laminates to withstand higher on flexural loading since the core of natural fibres seem at neutral position, only withstand smaller load caused from the bending. This investigation revealed that the arrangement of fibre in hybrid composite structure strongly affects its flexural strength and modulus.It was similarly found in the previous study on the effect of stacking sequence of carbon/basalt reinforced epoxy, hybrid composite laminates for load bearing structure [13], effects of interply hybridization on the damage resistance [18], mechanical behavior of stacking sequence in kenaf and banana fiber reinforced polyester [19] and hybrid composite laminates reinforced with kevlar/carbon/glass woven fabrics for ballistic impact testing [20].

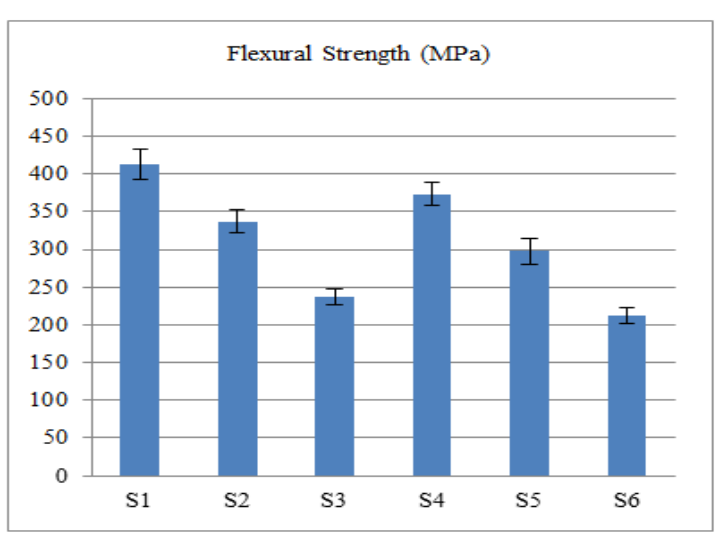

Figure 2(a). Flexural strength of hybrid composites

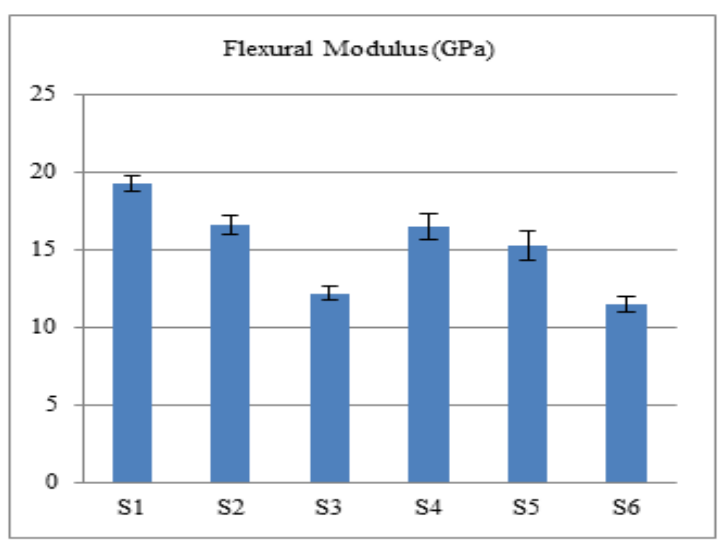

Figure 2(b). Flexural modulus of hybrid composites

\subsection{Effect of hybridization on flexural loading}

Effect of hybridization between glass/basalt, glass/jute and glass/flax was compared based on specific flexural strength and modulus as shown in Figure 3(a) and Figure 3(b). Glass/jute (S2) shows the highest specific flexural strength compared to glass/basalt (S1) and glass/flax (S3) with the different value of $5.1 \%$ and $35.6 \%$, respectively. In terms of stiffness, also glass/jute shows the highest stiffness value. These can be explained due to the lowest density of jute fibre which is $1.46 \mathrm{~g} / \mathrm{cm}^{3}$, compared with basalt and flax, $2.70 \mathrm{~g} / \mathrm{cm}^{3}$ and $1.50 \mathrm{~g} / \mathrm{cm}^{3}$, respectively. This result makes the jute fibre amongst the best selected material for high strength and stiffness to weight-ratio i.e. in structural application where bending loading is predominant.The present study agreed with the effect of hybridization on the materials selection as found by Reis et.al [21] in investigating the flexural behaviour of hybrid laminated composites using glass/hemp reinforced PP, effects of hybridization of glass/coir on tensile and flexural loadings [3], hybridization on the damage resistance of woven glass, woven carbon and UD carbon using drop impact [18] and mechanical characterization of hybrid composite laminates using basalt, flax, hemp and glass fibres [22]. 


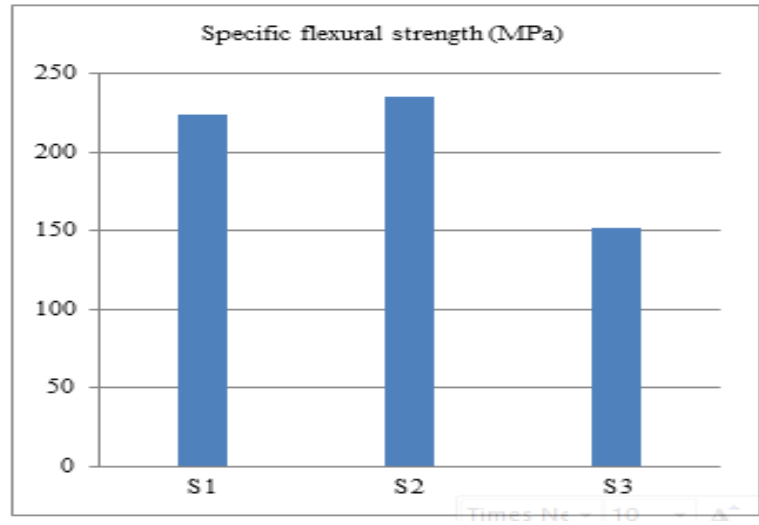

Figure 3(a). Specific flexural strength of hybrid composites

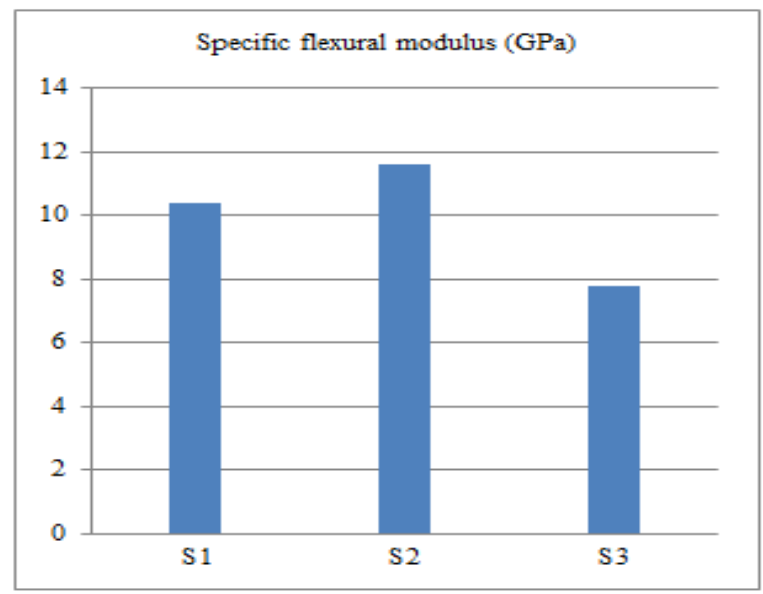

Figure 3(b). Specific flexural modulus of hybrid composites

\subsection{Fracture analysis}

Flexural strengths and modulus of hybrid structures of glass/basalt, glass/jute and glass/flax with SL sequence are higher than IC sequence and these can be explained in details by considering the cross-sectional area of failure mechanism as shown in Figure 4. Glass/basalt (Figure 4b) shows a laminate fail for a premature delamination at the interface between the basalt and glass layer caused by internal failure of the layers interface. This kind of failure was similar as evidenced in the glass/flax laminate (Figure 4f). It is interesting to note that delamination mechanism seems not happened as the presence of two glass layers rather than one in all hybrid structures (Figure 4a, Figure 4c and Figure 4e) which leads the stress gap between the glass layers and natural fibre layers to decrement. Delamination is one of the most common and dangerous failure mechanisms of the composite laminates under bending load which has been discovered in previous studies [23].Glass/jute with IC sequence exhibits an extensive degree of fibre pull-out and apparent that fibres have also been peeled from fracture surface (Figure 4d). Matrix cracking and fracture lines were performed on the surfaces that exhibited poor interfacial bond with the cracking at the early stages damage the matrix and glass layers then transfer to the jute fibre. The presence of glass on the next layer which adjacent to flax layer will slow down and blunted the damage propagation as shown in Figure 5.

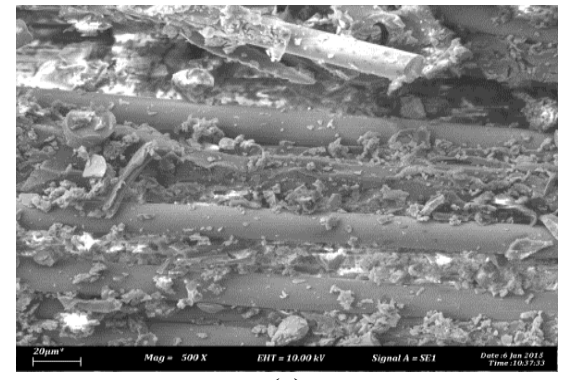

(a)

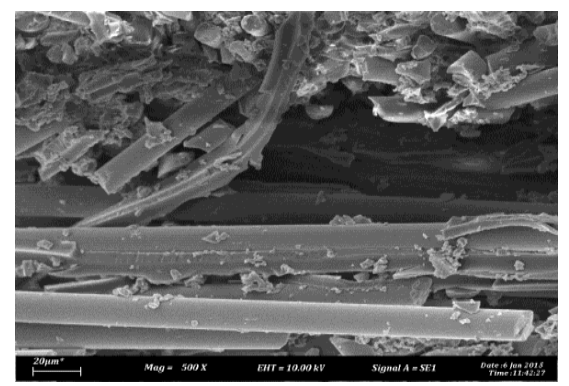

(b)

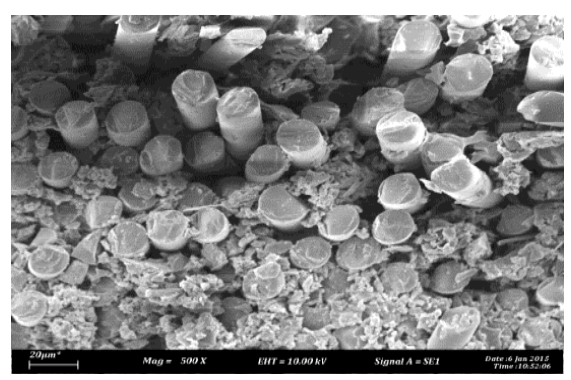

(c)

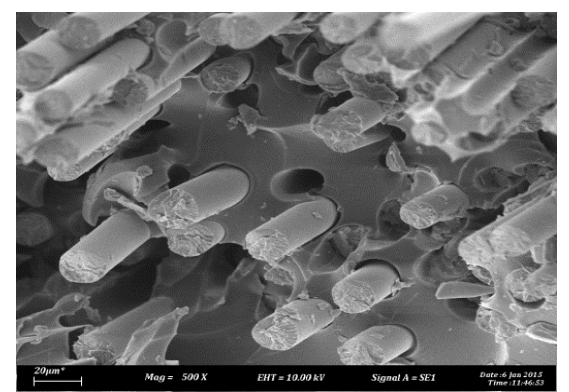

(d)

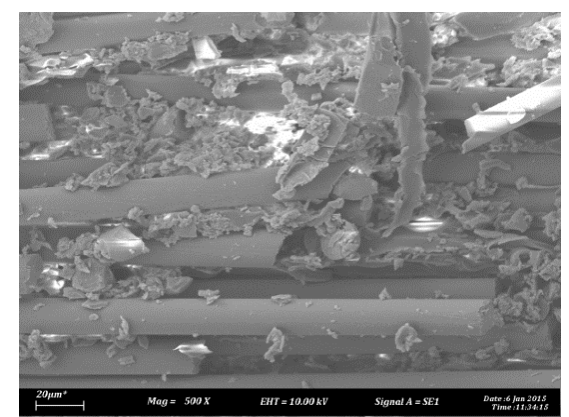

(e) 


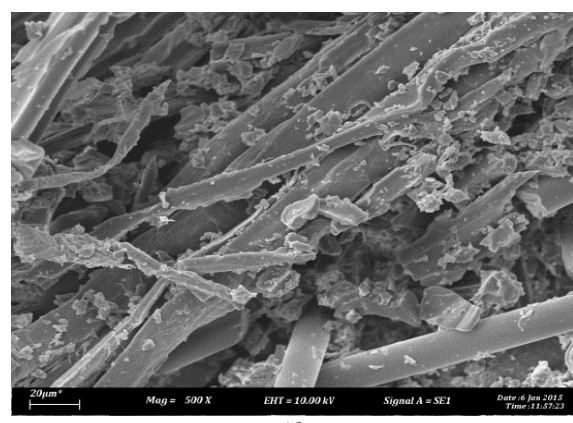

(f)

Figure 4. SEM micrographs of bending fracture of (a) glass/basalt (SL), (b) glass/basalt (IC), (c) glass/jute (SL), (d) glass/jute (IC), (e) glass/flax (SL), (f) glass/flax (IC)

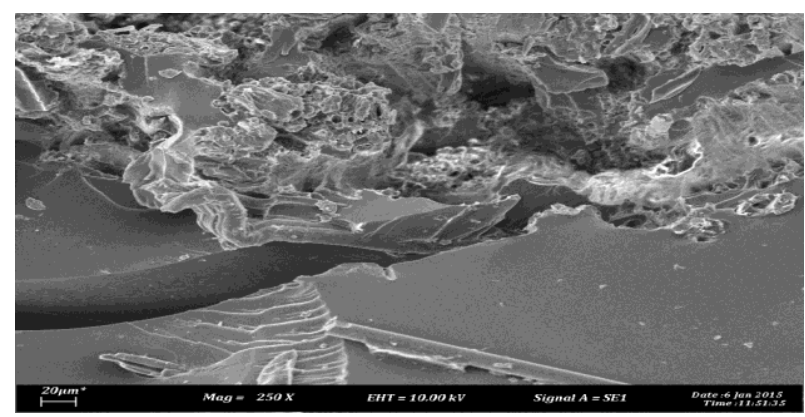

Figure 5. Matrix cracking of glass/jute hybrid laminate under flexural loading

\section{Conclusion}

The effects of stacking sequences of glass/basalt, glass/jute and glass/flax reinforced epoxy on flexural loadings have been investigated experimentally with two different configurations, SL and IC sequence. Specific properties were used to study the effect of hybridization between E-glass and natural fibres based on specific flexural strength and specific flexural modulus due to the different densities of the hybrid laminates considered here. From the results of the experimental test, it can be concluded that the stacking sequence was found to affect the flexural properties of the hybrid composites. Higher flexural strengths and modulus were obtained when two layers of glass were put at the extreme sides compared with IC sequence. On the effect of hybridization, the highest on specific flexural strength and modulus was achieved on glass/jute (S2) with the increasing value of $5.1 \%$ and $35.6 \%$ from glass/basalt (S1) and glass/flax (S3). SEM shows that the predominant failure modes of composite laminates are delamination and matrix cracking under flexural loadings. By varying the stacking sequences of the components of the hybrid composite, we can tailor the mechanical properties of the resulting hybrid material according to our target applications. However, more extensive work on the above lines with differing material parameters are needed to take full advantage of excellent strength and stiffness properties of all the hybrid configurations between glass/basalt, glass/jute and glass/flax.

\section{References}

1. H. Cheung, M. Ho, K. Lau, F. Cardona, and D. Hui, Natural fibre-reinforced composites for bioengineering and environmental engineering applications, Compos. Part B Eng., vol. 40, no. 7, pp. 655-663 (2009).

2. V. Fiore, G. Di Bella, and A.Valenza, Glassbasalt/epoxy hybrid composites for marine applications. Materials and design. vol. 32, no. 4, pp. 2091-2099, (2011).

3. S. Jayabal, U. Natarajan, and S. Sathiyamurthy, Effect of glass hybridization and stacking sequence on mechanical behaviour of interply coir-glass hybrid laminate, Bull. Mater. Sc, vol. 34, no. 2, pp. 293-298, (2011).

4. S. Mishra, A. Mohanty, L. Drzal, M. Misra, S. Parija, S. Nayak, and S. Tripathy, Studies on mechanical performance of biofibre/glass reinforced polyester hybrid composites, Compos. Sci. Technol., vol. 63, no. 10, pp. 1377-1385, (2003).

5. I. Civile, U. Instm, and U. Perugia, Mechanical and impact characterisation of hybrid composite laminates based on flax, hemp, basalt and glass fibers produced by vacuum infusion, 15th european conference on composite materials, (2012)

6. V. Lopresto, C. Leone, and I. De Iorio, Mechanical characterisation of basalt fibre reinforced plastic, Compos. Part B Eng., vol. 42, no. 4, pp. 717-723, (2011).

7. H. Bos, The Potential of Flax Fibres as Reinforcement for Composite Materials (2004).

8. I. M. De Rosa, C. Santulli, F. Sarasini, and M. Valente, Post-impact damage characterization of hybrid configurations of jute/glass polyester laminates using acoustic emission and IR thermography, Compos. Sci. Technol., vol. 69, no. 7-8, pp. 11421150, (2009).

9. B. A. Muralidhar, Tensile and compressive properties of flax-plain weave preform reinforced epoxy composites, J. Reinf. Plast. Compos., vol. 32, no. 3, pp. 207-213, (2012).

10. P. Banibayat and A. Patnaik, Variability of mechanical properties of basalt fiber reinforced polymer bars manufactured by wet-layup method, Materials and design, vol. 56, pp. 898-906, (2014).

11. K. S. Ahmed and S. Vijayarangan, Tensile, flexural and interlaminar shear properties of woven jute and jute-glass fabric reinforced polyester composites, J. Mater. Process. Technol., vol. 207, no. 1-3, pp. 330 335, (2008).

12. M. Jawaid, H. P. S. Abdul Khalil, and A. Abu Bakar, Woven hybrid composites: Tensile and flexural properties of oil palm-woven jute fibres based epoxy composites, Mater. Sci. Eng. A, vol. 528, no. 15, pp. 5190-5195, (2011).

13. J. Zhang, K. Chaisombat, S. He, and C. H. Wang, Hybrid composite laminates reinforced with glass/carbon woven fabrics for lightweight load bearing structures, Mater. and Des., vol. 36, pp. 75$80,(2012)$. 
14. I. D. G. Ary Subagia, Y. Kim, L. D. Tijing, C. S. Kim, and H. K. Shon, Effect of stacking sequence on the flexural properties of hybrid composites reinforced with carbon and basalt fibers, Compos. Part B Eng., vol. 58, pp. 251-258, (2014).

15. S. D. Pandita, X. Yuan, M. A. Manan, C. H. Lau, A. S. Subramanian, and J. Wei, Evaluation of jute/glass hybrid composite sandwich: Water resistance, impact properties and life cycle assessment, J. Reinf. Plast. Compos., vol. 33, no. 1, pp. 14-25, (2013).

16. S. Nunna, P. R. Chandra, S. Shrivastava, and AK. Jalan, A review on mechanical behavior of natural fiber based hybrid composites, J. Reinf. Plast. Compos., vol. 31, no. 11, pp. 759-769, (2012).

17. ASTM D790-10: Standard test methods for flexural properties of unreinforced and reinforced plastics and electrical insulating materials." Annual Book of ASTM Standards, United States, (2010).

18. E. V. González, P. Maimí, J. R. Sainz de Aja, P. Cruz, and P. P. Camanho, Effects of interply hybridization on the damage resistance and tolerance of composite laminates, Compos. Struct., vol. 108, pp. 319-331, (2014).

19. P. Samivel, Mechanical behavior of stacking sequence in kenaf and banana fiber reinforcedpolyester laminate, Int. J. Mech. Eng. Robot. Res., vol. 2, (2013)

20. E. Randjbaran, R. Zahari, N. A. A. Jalil, and D. L. A. A. Majid, Hybrid composite laminates reinforced with Kevlar/carbon/glass woven fabrics for ballistic impact testing., ScientificWorldJournal, (2014).

21. P. N. B. Reis, J. a. M. Ferreira, F. V. Antunes, and J. D. M. Costa, Flexural behaviour of hybrid laminated composites, Compos. Part A : Appl. Sci. Manuf., vol. 38, no. 6, pp. 1612-1620, (2007).

22. R. Petrucci, C. Santulli, D. Puglia, F. Sarasini, L. Torre, and J. M. Kenny, Mechanical characterisation of hybrid composite laminates based on basalt fibres in combination with flax, hemp and glass fibres manufactured by vacuum infusion, Mater. and Des. vol. 49, pp. 728-735, (2013).

23. V.Fiore, G. Di Bella, and A. Valenza, Glassbasalt/epoxy hybrid composites for marine applications, Mater. and Des. vol. 32, (2011). 